\title{
Keterlambatan Pengumpulan Berkas Verifikasi Klaim BPJS di RS X: Apa Akar Masalah dan Solusinya?
}

Estri Aditya Pradani*, Dewi Lelonowati, Sujianto

* Penulis Korespondensi: estriadipradani@gmail.com

Klinik Rawat Inap Ramdani Husada, Malang

\begin{tabular}{l}
\hline IND EXING \\
\hline Keywords: \\
Feedback; \\
BPJS verification file; \\
BPJS claim; Installation \\
of Financial \\
Guarantees;
\end{tabular}

Kata kunci:

Umpan balik; Berkas verifikasi klaim BPJS;

Klaim BPJS; Instalasi Jaminan Pembiayaan (IJP);

\begin{abstract}
A B S TR A C T
This study aims to analyze root problems and the best solution of entry delays in the BPJS claim verification file to IJP (Installation of Financing Guarantee) of the hospital. This research is a qualitative descriptive research using Focus Group Discussion, Fishbone diagram and "5 Why" question methods to find the root problems. After that, the choice of alternative solutions is determined by Nominal Group Technique (NGT) and Capability Accessibility Readiness and Leverage (CARL) methods. This activity involves 2 management staffs, 3 IJP staffs, 2 pharmacists, and 7 nurses from emergency department, outpatient and inpatient units. The result of this research is written feedback by IJP for all outpatient and inpatient unit as the best solution which is expected to overcome the entry delays problem.
\end{abstract}

Penelitian ini bertujuan untuk menganalisis akar masalah dan solusi terbaik keterlambatan pengumpulan berkas verifikasi klaim BPJS ke IJP (Instalasi Jaminan Pembiayaan) di rumah sakit. Penelitian ini merupakan penelitian deskriptif kualitatif yang menggunakan metode Focus Group Discussion, diagram Fishbone dan pertanyaan "5 Why" untuk mencari akar masalah. Setelah diketahui akar masalah dilakukan pemilihan alternatif solusi dengan metode Nominal Group Technique (NGT) dan Capability Accessibility Readiness and Leverage (CARL). Kegiatan ini melibatkan 2 staf manajemen, 3 staf IJP, 2 petugas apotik, dan 7 perawat IGD, rawat jalan dan rawat inap. Hasil penelitian ini adalah solusi terbaik berupa pembuatan umpan balik tertulis oleh IJP untuk seluruh unit pelayanan rawat jalan dan rawat inap yang diharapkan dapat mengatasi keterlambatan pengumpulan berkas verifikasi klaim BPJS ke IJP.

C 2017 JMMR All rights reserved

\section{PENDAHULUAN}

Sejak dicanangkan pada tahun 2014, sistem Jaminan Kesehatan Nasional (JKN) mempengaruhi semua rumah sakit dalam segala aspek. Pada tanggal 1 September 2016, peserta program JKN telah mencapai 168.512 .237 jiwa atau sekitar $67 \%$ dari total penduduk Indonesia yang ditargetkan menjadi $100 \%$ pada tahun 2019.6,11 Peningkatan jumlah peserta JKN ini terjadi karena kewajiban yang ditetapkan oleh pemerintah dan peningkatan kualitas pelayanan terhadap pasien BPJS di Indonesia.

Penelitian-penelitian sebelumnya meneliti efek asuransi pemerintah yang menggunakan sistem DRG (Diagnosis Related Group) based payment seperti JKN terhadap rumah sakit. Cheng et al, (2012) dan Mutia (2016) menunjukkan bahwa di negara-negara Eropa, Amerika, maupun di Indonesia, sistem asuransi ini menyebabkan penurunan $10 \%$ length of stay pasien tanpa menyebabkan banyak perubahan dalam outcome pelayanan kesehatan. ${ }^{9,14}$
Menurut Wild et al., (2012) dan Rauner dan SchaffhauserLinzatti (2013) sistem ini dapat meningkatkan transparansi dan efisiensi serta menekan biaya kesehatan. ${ }^{17,19}$ Namun Yavari et al. (2015) menyebutkan sistem ini juga memiliki dampak negatif bagi rumah sakit karena sistem mentransfer sejumlah uang tanpa mempedulikan aktivitas rumah sakit, sehingga sangat mungkin terjadi inefisiensi dan konflik di antara stakeholder di rumah sakit. Alokasi untuk sumber daya rumah sakit tetap harus dibayar, sedangkan aktivitas yang dikerjakan bervariasi. ${ }^{20}$ Yavari et al. (2015), Budiarto dan Sugiharto, (2013), dan Cheng et al. (2012) menyebutkan efek berupa peningkatan transparansi biaya dan aktivitas, penahanan untuk tidak menambah pengeluaran rumah sakit, pengoptimalan sumber daya rumah sakit, pengurangan pelayanan yang tidak perlu, pengurangan length of stay dan kemungkinan pasien kembali, susbtitusi pasien rawat inap dengan rawat jalan, perubahan struktur pelayanan, dan pembuatan panduan praktek yang homogen. $3,9,20$ 
Mathauer dan Wittenbecher (2013) menyebutkan bahwa rumah sakit di negara dengan income yang rendah atau menengah disarankan untuk meningkatkan kerjasama internal maupun eksternal untuk meningkatkan kebenaran data yang dimiliki dan kinerja manajemen klaim. ${ }^{13}$ Fässler et al. (2015) menyatakan bahwa bagi dokter, pelayanan dengan sistem ini dinilai lebih baik, namun terjadi penurunan dalam orientasi terhadap pasien dan tidak semua prinsip yang ideal dapat diterapkan. ${ }^{12} \mathrm{Wu}$ dan Shen (2014) dalam Peprah dan Atarah (2014) menyatakan apabila provider tidak mendapatkan kecukupan pembiayaan, akan terjadi pengaruh berupa penurunan kualitas pelayanan terhadap pasien 16 dan menurut Or (2014) diperlukan suatu sistem informasi yang kuat untuk memonitor keuangan dan kualitas pelayanan. ${ }^{15}$ Saat ini belum ada penelitian yang membahas masalah keterlambatan klaim asuransi pemerintah, alasan penyebabnya maupun solusinya sehingga penulis tertarik untuk melakukan penelitian ini.

RS X merupakan RS milik pemerintah dengan status BLUD (Badan Layanan Umum Daerah). Sejak 18 Mei 2015, rumah sakit ini ditetapkan sebagai Rumah Sakit Rujukan Regional yang mengampu rujukan dari wilayah Kabupaten Trenggalek, Kota Blitar, Kabupaten Blitar dan Kabupaten Pacitan. Pada tanggal 25 Mei 2016, rumah sakit ini ditetapkan sebagai rumah sakit Tipe B Pendidikan. Jumlah pasien umum rumah sakit ini pada tahun 2016 semakin menurun, dan pasien BPJS makin meningkat. Pasien rawat inap umum tercatat sebanyak $38 \%$ dari total pasien, sedangkan pasien rawat jalan umum sekitar 29\%, dan jumlah pemakai asuransi selain BPJS Kesehatan semakin menurun.

Gambaran tingkat pemanfaatan dan efisiensi sarana pelayanan serta mutu pelayanan di rumah sakit ini pada tahun 2016 berdasarkan data bulan Januari hingga Mei ialah meliputi BOR (Bed Occupancy Rate) 79,36\%, ALOS (Length Of Stay) 4,36 hari, BTO (Bed Turn Over) 27,56 kali, TOI (Turn Over Interval) 1,14 hari, GDR (Gross Death Rate) $86,71 \%$ dan NDR (Net Death Rate) 59,31\%. Terjadi peningkatan pada BOR sebesar 5,65\%, penurunan ALOS sebesar 0,06 hari, penurunan BTO sebesar 33,56 kali, peningkatan TOI sebesar 0,44 hari, peningkatan GDR 0,49\% dan NDR 0,53\% dibandingkan dengan tahun 2015 . Hal ini menunjukkan peningkatan jumlah pasien dan peningkatan efisiensi sarana pelayanan rumah sakit, namun peningkatan BOR ini di sebagian besar ruangan mayoritas diisi oleh pasien BPJS Kesehatan. ${ }^{18}$

Alur rekam medis dan pembiayaan pasien BPJS Kesehatan di RS X tidak berada dalam satu jalur. Rekam medis dikelola oleh Instalasi Rekam Medis, sedangkan berkas pembiayaan untuk klaim dikelola oleh Instalasi Jaminan Pembiayaan (IJP). Data-data ekspedisi rekam medis di IJP menunjukkan sering terjadi keterlambatan baik kelengkapan pengisian rekam medis, maupun keterlambatan dalam hari pengantaran ke IJP yang bervariasi antara 7-162 hari oleh unit rawat jalan dan terlama mencapai 131 oleh unit rawat inap. Data ekspedisi juga menyebutkan meskipun rekam medis telah dilengkapi, berkas verifikasi tidak langsung diserahkan ke IJP melainkan ditunggu agar terkumpul di ruang unit pelayanan. Keterlambatan ini berakibat tidak tercapainya target masuknya berkas tahap I setiap bulan. Prosentase berkas verifikasi rawat jalan yang diterima verifikator BPJS pada tahap I bulan April, Juni dan Juli 2016 menunjukkan rerata $60 \%$ dari target $90-100 \%$, sementara itu prosentase berkas verifikasi rawat inap pada tahap I bulan April, Mei, Juni dan Juli 2016 berada di bawah 50\%. Hal ini berakibat makin besarnya prosentase berkas yang masuk pada tahap II dan berpotensi memunculkan tahap III. Semakin terlambat berkas yang masuk ke verifikator BPJS semakin terlambat dana yang turun ke rumah sakit (Gambar 1 dan 2). ${ }^{7}$

Fokus penelitian ini adalah mencari akar masalah dan solusi untuk mengatasi keterlambatan pengumpulan berkas verifikasi BPJS ke IJP rumah sakit. Keterlambatan klaim terjadi karena kegagalan capaian target pengumpulan berkas verifikasi. Hal ini tidak menguntungkan bagi rumah sakit karena rumah sakit ini merupakan pusat rujukan regional, sehingga pelayanan dituntut agar diberikan semaksimal mungkin tanpa ada kendala dalam hal pembiayaan.

Hasil penelitian ini diharapkan dapat memberikan kontribusi secara teoritis yaitu mengetahui gambaran klaim asuransi BPJS rumah sakit di Indonesia. Secara praktis penelitian ini membantu kelancaran klaim BPJS di RS X sehingga pelayanan dan kegiatan operasionalnya tidak terhambat akibat tidak tercukupinya dana yang diperlukan.

\section{METODE PENELITIAN}

Penelitian ini merupakan penelitian deskriptif kualitatif. Untuk mencari akar masalah dilakukan FGD (Focus Group Discussion) dengan bantuan diagram Fishbone (Gambar 3). Selanjutnya dengan pertanyaan "5 Why" terhadap cabang sirip ikan, dicari akar penyebab masalah. Setelah didapatkan akar masalah, selanjutnya dicari alternatif solusinya. Proses ini melibatkan 2 staf manajemen, 3 staf IJP, 2 petugas apotik, 7 perawat IGD, poli dan rawat inap. Proses pemilihan alternatif solusi pada masalah dilakukan 
dengan metode NGT (Nominal Group Technique). NGT dilaksanakan tanpa intervensi anggota yang lain. Semua anggota menuliskan skor 1 sampai 5 setiap alternatif solusi sesuai kriteria yang ditentukan. Penapisan dilakukan terhadap pilihan solusi berdasarkan hasil skor dikalikan bobot sesuai kriteria kemudian dijumlahkan

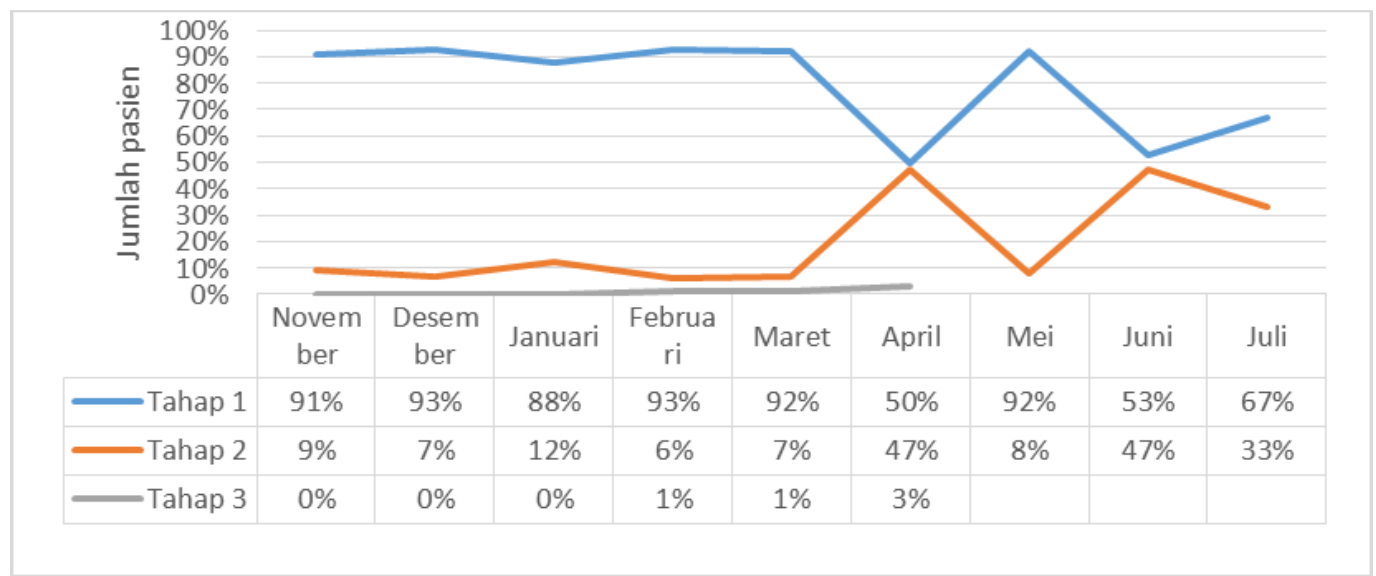

Gambar 1. Data Absensi Berkas Rawat Jalan (dalam \%).

Sumber: BPJS Center RS X

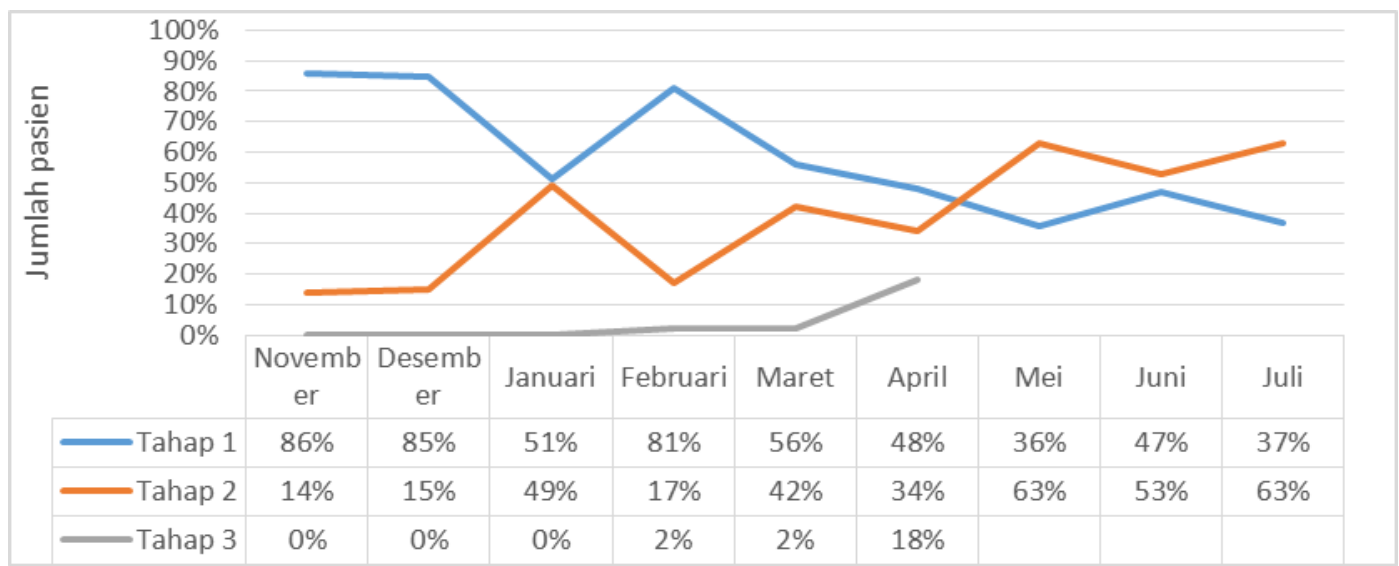

Gambar 2. Data Absensi Berkas Rawat Inap (dalam \%)

Sumber: BPJS Center RS X

untuk menentukan ranking. Selanjutnya alternatif solusi ditapis lagi dengan metode CARL yang didasarkan pada kriteria yang harus diberi skor $0-4$ yaitu: $\mathrm{C}=$ Capability (ketersediaan sumber daya misalnya dana, sarana, dan peralatan), $\mathrm{A}=$ Accessibility (kemudahan masalah untuk diatasi atau tidak, kemudahan dapat didasarkan pada ketersediaan metode/cara/teknologi serta penunjang pelaksana seperti peraturan), $\mathrm{R}=$ Readiness (kesiapan tenaga pelaksana maupun sasaran, seperti keahlian atau kemampuan motivasi) dan $\mathrm{L}=$ Leverage (besarnya pengaruh kriteria satu dengan yang lain dalam pemecahan masalah yang dibahas).

\section{HASIL DAN PEMBAHASAN}

Ditemukan bahwa 5 akar masalah penyebab keterlambatan berkas verifikasi ke IJP ialah sebagai berikut: (1) belum ada reward and punishment bagi dokter penanggungjawab yang tidak melengkapi rekam medis $1 \times 24$ jam, (2) belum ada umpan balik secara rutin dari IJP mengenai kepatuhan pengembalian berkas verifikasi $2 \times 24$ jam, (3) belum ada SOP mengenai tata cara pengembalian berkas verifikasi ke IJP, (4) belum ada kebijakan reward and punishment bagi unit yang belum menginput data $100 \%$ pada SIM-RS, dan (5) belum meminta kepada tim SIM-RS untuk membuat program yang dapat mengetahui data pasien KRS setiap hari yang terhubung ke IJP. 
Berdasarkan diskusi dengan metode NGT dan CARL didapatkan alternatif solusi sebagaimana dijelaskan dalam Tabel 1 dan 2. Berdasarkan metode tersebut maka terpilih solusi terbaik (ranking 1) berupa pembuatan umpan balik tertulis oleh IJP kepada seluruh unit rawat jalan dan rawat inap mengenai ketepatan pengembalian berkas ke IJP 2x24 jam.

Menurut data IJP RS X terjadi selisih antara nilai pengajuan dan nilai realisasi klaim yang cenderung meningkat yaitu dari Rp 8.830.200,- pada bulan Februari menjadi Rp 950.858.100,- pada bulan Juni 2016. Selisih ini diakibatkan oleh masih adanya kekurangan berkas verifikasi yang perlu diperbaiki. Hal ini sangat mungkin terjadi karena berkas verifikasi yang masuk pada tahap I tidak mencapai target $90-100 \%$. Apabila berkas pada tahap I mencapai target, maka perbaikan yang diminta oleh petugas verifikator BPJS dapat dilakukan dengan cepat dan segera diproses pada tahap II. Namun, apabila kurang dari target maka berkas akan menumpuk pada tahap II sehingga apabila diperlukan perbaikan akan masuk pada tahap III atau IV yang jatuh pada bulan berikutnya. Hal ini berakibat pada tertundanya dana yang turun untuk rumah sakit. Dana yang seharusnya selesai dalam 2 tahap mengalami prolong yang ditandai dengan munculnya turunnya dana tahap ketiga. Pada bulan Februari, Maret dan April 2016 terjadi tahap III turunnya dana, dengan yang terbesar terjadi pada bulan April sebesar Rp 2.133.285.700,- untuk klaim rawat inap dan Rp 53.420.900,- untuk klaim rawat jalan.

Penelitian ini menemukan bahwa salah satu akar masalah penyebab keterlambatan penyerahan berkas verifikasi disebabkan oleh tidak adanya umpan balik tertulis oleh IJP. Selama ini, tidak ada umpan balik yang terprogram dan menyeluruh untuk semua unit rawat jalan dan rawat inap, sehingga masalah ini tidak pernah dapat diselesaikan. Unit rawat jalan dan rawat inap juga tidak mengetahui kesalahan unit masing-masing yang berkontribusi menyebabkan keterlambatan klaim BPJS turun ke rumah sakit. Umpan balik tertulis ini diharapkan agar dapat menjadi sarana sosialisasi sekaligus evaluasi terhadap seluruh unit yang selama ini kurang maksimal kinerjanya dalam pengantaran berkas ke IJP. Umpan balik ini juga dapat mengatasi masalah lainnya, yaitu ketidakpatuhan DPJP (Dokter Penanggung Jawab Pasien) dalam melengkapi rekam medis, yang menurut Tabel 1 merupakan akar masalah yang paling sulit untuk diselesaikan.

Umpan balik merupakan bagian dari pengembangan organisasi, pengembangan sumber daya manusia dan perubahan organisasi. ${ }^{1,4,5,10}$ Perubahan terhadap suatu organisasi meliputi kegiatan:

1) Masuk dan Membuat Kontrak; Masuk untuk mendapatkan data agar mengerti permasalahan organisasi, kemudian membuat kontrak dengan pihak manajemen dan staf yang terlibat untuk membuat perubahan terencana.

2) Mendiagnosis; Mengumpulkan, menganalisis dan memberikan umpan balik terhadap data yang ditemukan. Umpan balik merupakan kegiatan yang paling penting karena merupakan pengorganisasian data sehingga bermakna dan dapat dimengerti oleh manajemen dan staf.

3) Merencanakan dan melaksanakan intervensi yang akan dilakukan, dan mengendalikan pelaksanaan intervensi. 


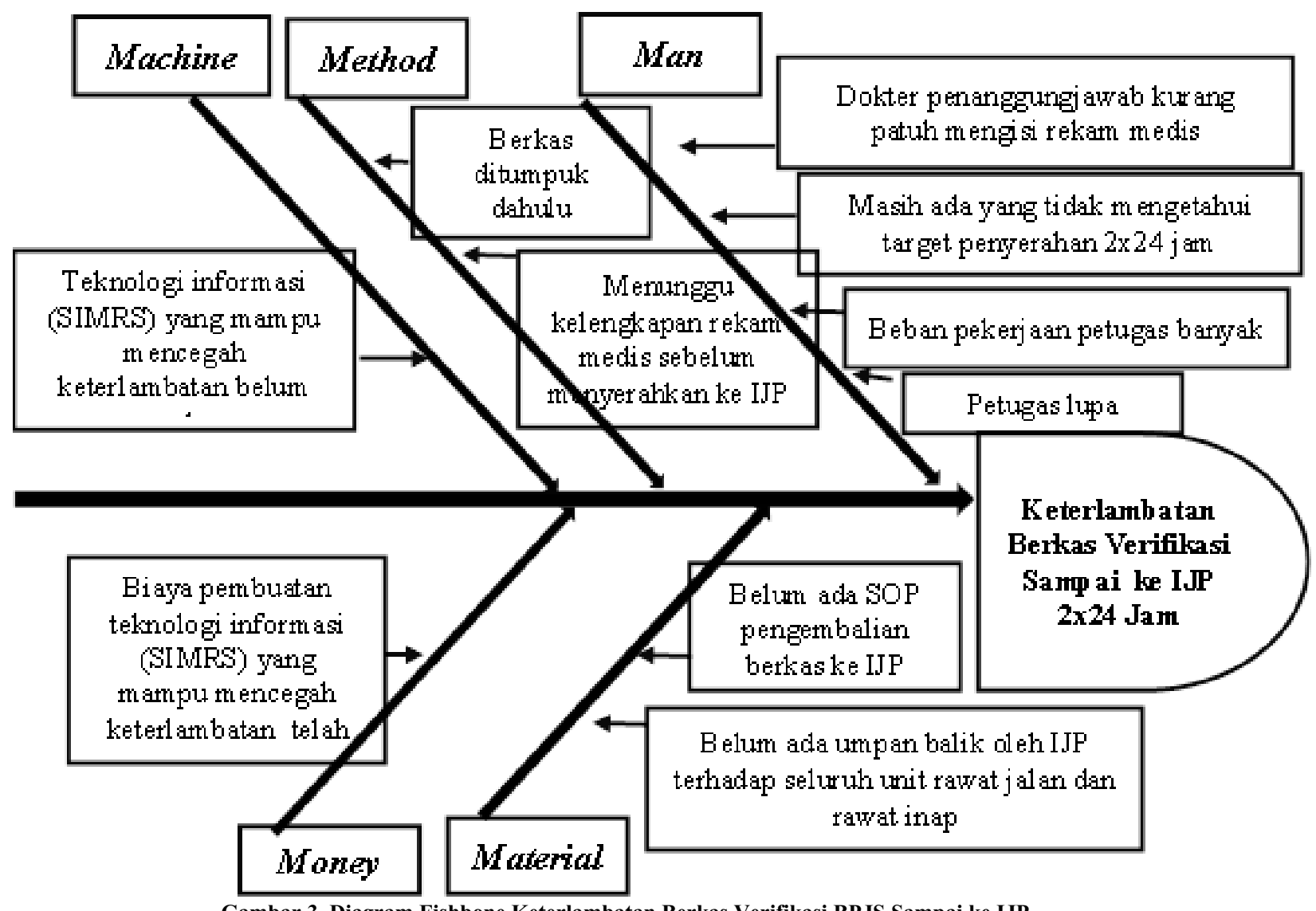

Gambar 3. Diagram Fishbone Keterlambatan Berkas Verifikasi BPJS Sampai ke IJP

Tabel 1.Pilihan Solusi Terbaik dengan Menggunakan Metode NGT

\begin{tabular}{|c|c|c|c|c|c|c|c|}
\hline \multicolumn{2}{|c|}{ Pilihan solusi } & \multirow{2}{*}{$\begin{array}{c}\text { Ke-mudahan } \\
\text { penerapan } \\
0,2 \\
\end{array}$} & \multirow{2}{*}{$\begin{array}{c}\begin{array}{c}\text { Kemungkinan } \\
\text { berhasil }\end{array} \\
0,2 \\
\end{array}$} & \multirow{2}{*}{$\begin{array}{c}\begin{array}{c}\text { Ef-ektifitas } \\
\text { solusi }\end{array} \\
0,5 \\
\end{array}$} & \multirow{2}{*}{$\begin{array}{c}\text { Ham-batan } \\
\text { relatif } \\
\text { rendah } \\
0,1\end{array}$} & \multirow{2}{*}{$\begin{array}{c}\text { Nilai total } \\
1,0\end{array}$} & \multirow[t]{2}{*}{ Ranking } \\
\hline & & & & & & & \\
\hline 1. & $\begin{array}{l}\text { Pembuatan umpan balik } \\
\text { oleh IJP ke seluruh unit } \\
\text { mengenai retepatan } \\
\text { waktu pengembalian } \\
\text { berkas } 2 \times 24 \text { jam }\end{array}$ & $\begin{array}{c}5 \\
(1)\end{array}$ & $\begin{array}{c}5 \\
(1)\end{array}$ & $\begin{array}{c}5 \\
(2,5)\end{array}$ & $\begin{array}{c}5 \\
(0,5)\end{array}$ & 5 & I \\
\hline 2. & $\begin{array}{l}\text { Membuat SOP tata cara } \\
\text { pengembalian berkas } \\
\text { verifikasi ke IJP dengan } \\
\text { target } 2 \times 24 \text { jam }\end{array}$ & $\begin{array}{c}4 \\
(0,8)\end{array}$ & $\begin{array}{c}4 \\
(0,8)\end{array}$ & $\begin{array}{c}4 \\
(2)\end{array}$ & $\begin{array}{c}3 \\
(0,3)\end{array}$ & 3,9 & II \\
\hline 3. & $\begin{array}{l}\text { Membuat SK mengenai } \\
\text { reward and punishment } \\
\text { bagi unit yang belum } \\
\text { menginput } 100 \%\end{array}$ & $\begin{array}{c}4 \\
(0,8)\end{array}$ & $\begin{array}{c}4 \\
(0,8)\end{array}$ & $\begin{array}{c}3 \\
(1,5)\end{array}$ & $\begin{array}{c}3 \\
(0,3)\end{array}$ & 3,4 & III \\
\hline
\end{tabular}


Lanjutan Tabel 1.Pilihan Solusi Terbaik dengan Menggunakan Metode NGT

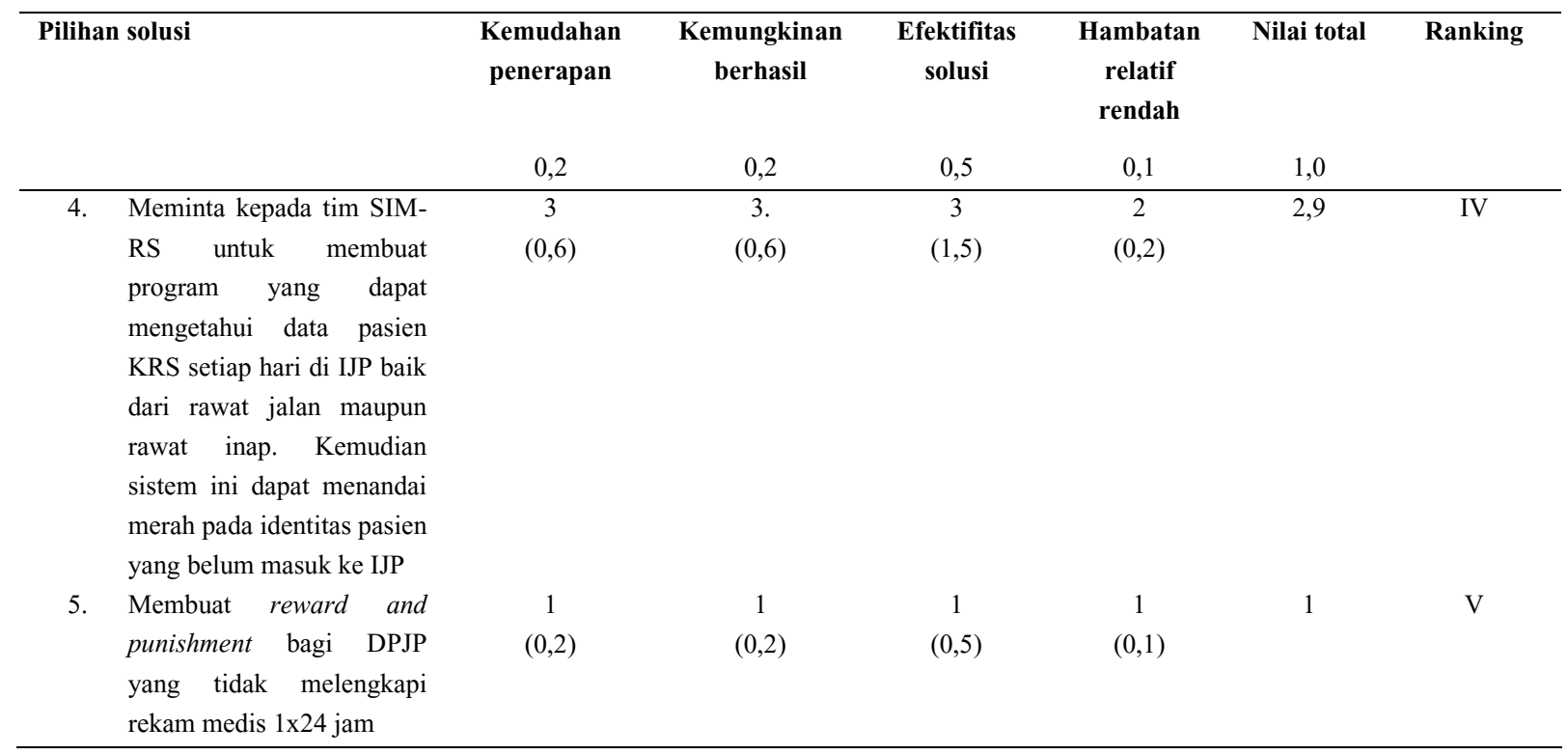

Tabel 2. Pilihan Solusi Terbaik dengan Menggunakan Metode $C A R L$

\begin{tabular}{|c|c|c|c|c|c|c|c|}
\hline & $\begin{array}{c}\text { Alternatif } \\
\text { Solusi }\end{array}$ & $\begin{array}{c}\text { Capa-bility } \\
(1-4)\end{array}$ & $\begin{array}{c}\text { Accessi- } \\
\text { bility } \\
(1-4)\end{array}$ & $\begin{array}{c}\text { Readiness } \\
\text { (1-4) }\end{array}$ & $\begin{array}{c}\text { Leverage } \\
(1-4)\end{array}$ & $\begin{array}{c}\text { Jumlah } \\
\text { skor }\end{array}$ & Ranking \\
\hline 1. & $\begin{array}{l}\text { Pembuatan umpan balik oleh IJP } \\
\text { ke seluruh unit mengenai } \\
\text { ketepatan waktu pengembalian } \\
\text { berkas } 2 \times 24 \text { jam }\end{array}$ & 4 & 4 & 4 & 4 & 256 & I \\
\hline 2. & $\begin{array}{l}\text { Membuat SOP tata cara } \\
\text { pengembalian berkas verifikasi ke } \\
\text { IJP dengan target } 2 \times 24 \text { jam }\end{array}$ & 4 & 4 & 4 & 2 & 128 & II \\
\hline 3. & $\begin{array}{l}\text { Membuat SK mengenai reward } \\
\text { and punishment bagi unit yang } \\
\text { belum menginput } 100 \%\end{array}$ & 3 & 3 & 3 & 3 & 81 & III \\
\hline 4. & $\begin{array}{l}\text { Meminta kepada tim SIM-RS } \\
\text { untuk membuat program yang } \\
\text { dapat mengetahui data pasien } \\
\text { KRS setiap hari di IJP baik dari } \\
\text { rawat jalan maupun rawat inap. } \\
\text { Kemudian sistem ini dapat } \\
\text { menandai merah pada identitas } \\
\text { pasien yang belum masuk ke IJP }\end{array}$ & 3 & 2 & 2 & 3 & 36 & IV \\
\hline 5. & $\begin{array}{l}\text { Membuat reward and punishment } \\
\text { bagi DPJP yang tidak melengkapi } \\
\text { rekam medis } 1 \times 24 \text { jam }\end{array}$ & 2 & 1 & 1 & 4 & 8 & V \\
\hline
\end{tabular}

4) Mengevaluasi efek perubahan yang telah diimplementasikan, kemudian membuat program yang sukses untuk agar dapat senantiasa ada yaitu dengan melakukan umpan balik, pemberian penghargaan, dan pelatihan. ${ }^{10}$
Umpan balik yang baik ialah yang dapat membuat organisasi bangkit untuk menyelesaikan masalah, dapat meringkas maksud dan arti data yang didapatkan, tidak terlalu banyak, sehingga organisasi tidak merasa perubahan tidak mungkin dilakukan. Umpan balik yang baik memiliki 
kriteria: (1) relevan, artinya anggota organisasi merasa data tersebut memiliki makna, (2) mudah dimengerti, dapat menggunakan grafik atau chart, (3) deskriptif, dapat segera dihubungkan dengan perilaku nyata organisasi sehari-hari, dapat diberi contoh dan ilustrasi, (4) valid dan akurat, dan (5) tepat waktu, artinya harus segera diberikan kepada anggota organisasi dianalisis. ${ }^{10}$

Umpan balik yang dibagi kepada seluruh unit akan membawa dampak positif bagi perusahaan. Penelitian menyebutkan bahwa umpan balik berdampak positif pada dua hal yaitu variabel hasil (produktivitas, keuangan) dan variabel proses (keterbukaan, pengambilan keputusan, dan motivasi karyawan). Umpan balik sebaiknya dikombinasikan dengan kegiatan lain misalnya konsultasi dan pelatihan tim. Apabila hanya dengan umpan balik tingkat keberhasilan intervensi ialah sebesar 33\%, sedangkan dengan pelatihan tim tingkat keberhasilan akan meningkat menjadi $45 \%{ }^{8}$

Umpan balik memiliki keterbatasan yaitu dapat membuat: Ambiguitas tujuan artinya perbedaan pengertian tujuan penulisan umpan balik antara penulis dan penerima sehingga menghambat penyelesaian masalah. Ketidakpercayaan dengan umpan balik karena tidak anonim. Topik-topik sensitif yang tidak ingin diperiksa. Anggapan bahwa pengerjaan umpan balik dapat mengganggu pekerjaan utama. ${ }^{10}$ Umpan balik tertulis sebagai bagian dari manajemen modal kerja harus senantiasa didukung oleh manajemen rumah sakit, selalu dikomunikasikan dengan seluruh unit, diberikan insentif bagi pelaksananya dan unit yang dapat mengevaluasi diri dengan baik, dan selalu dikontrol pelaksanaannya. Apabila hal ini dilakukan, hasilnya akan dapat dirasakan kurang dari setahun, meningkatkan potensi perusahaan sebesar $30 \%$ pada tahun pertama, dan optimalisasi secara keseluruhan membutuhkan 3 tahun, tergantung ukuran rumah sakit. Berdasarkan pengalaman, $40 \%$ potensi berikutnya dapat direalisasikan pada tahun kedua, dan sisanya (sekitar 30\%) pada tahun ketiga. $^{2}$

\section{SIMPULAN}

Keterlambatan berkas verifikasi BPJS masuk ke IJP lebih dari $2 \times 24$ jam yang disebabkan lambatnya pengisian rekam medis oleh DPJP dan pengantarannya ke ruang IJP menyebabkan keterlambatan turunnya dana BPJS ke rumah sakit. Umpan balik tertulis merupakan solusi terbaik untuk mengatasi masalah tersebut. Apabila hal ini sukses dilaksanakan, dapat terjadi perubahan-perubahan positif bagi rumah sakit dalam hal manajemen klinis dan keuangan rumah sakit. Keterbatasan penelitian ini ialah penelitian dilakukan di rumah sakit milik pemerintah dengan status BLUD, sehingga dapat berbeda kondisinya dengan rumah sakit swasta. Setiap rumah sakit mempunyai metode masing-masing untuk menangani klaim pasien BPJS sehingga penyebab dan solusi pemecahannya tidak selalu sama dengan RS X.

Direkomendasikan agar rumah sakit membuat umpan balik tertulis secara berkesinambungan. Disarankan agar dilakukan penelitian selanjutnya pada RS swasta peserta BPJS untuk membandingkan penyebab dan solusi keterlambatan terkumpulnya berkas verifikasi klaim BPJS..

\section{DAFTAR PUSTAKA}

1. Anderson, D. L. (2013). Organizational Development: The Process of Leading Organizational Change. California: SAGE Publication, Inc.

2. Buchmann, P. dan Jung, U. (2008). Best-Practice Working Capital Management: Techniques for Optimizing Inventories, Receivables, and Payables. Retrieved from http://www.financepractitioner.com

3. Budiarto, W. dan Sugiharto, M. (2013). Biaya Klaim Ina-CBGs dan Biaya Riil Penyakit Katastropik Rawat Inap Peserta Jamkesmas di Rumah Sakit Studi di 10 Rumah Sakit Milik Kementerian Kesehatan JanuariMaret 2012. Buletin Penelitian Sistem Kesehatan. Volume 16. Surabaya: Airlangga University Press

4. Burke. W. W. (2013). Organization Change: Theory and Practice. California: SAGE Publication Inc.

5. Burke W. W. dan Noumair D. A. (2015). Organization development: A Process of Learning and Changing (third ed). New Jersey: Pearson Education Inc.

6. BPJS Kesehatan RI. (2016) Data Peserta BPJS. Retrieved from: https://bpjskesehatan.go.id

7. BPJS Kesehatan RI. (2014). . Petunjuk Teknis Verifikasi Klaim. Retrieved from: https://bpjskesehatan.go.id/bpjs/dmdocuments/Petunju k\%20Teknis\%20Verifikasi\%20Klaim_REV.pdf

8. Carter, L., Ulrich, D. dan Goldsmith, M. (2012). Best Practices in Leadership Development and Organization Change: How the Best Companies Ensure Meaningful Change and Sustainable Leadership. John Wiley \& Sons, Inc.

9. Cheng, S.H., Chen, C.-C. \& Tsai, S.L. (2012). The Impacts of DRG-Based Payments on Healthcare Provider Behaviors Under a Universal Coverage System: a Population-Based Study. Health Policy. Volume 107, 202-208. 
10. Cummings, T. G. dan Worley, C. G. (2014). Organization Development and Change. Cengage learning.

11. Depkes RI. (2014). Peraturan Menteri Kesehatan Republik Indonesia Nomor 28 Tahun 2014 Tentang Pedoman Pelaksanaan Program Jaminan Kesehatan Nasional. Retrieved from: http://www.depkes.go.id/pdf.php?id=MCN20143250002

12. Fassler, M., Wild, V., Clarinval, C., Tschopp, A., Faehnrich, J. A. \& Biller-Andorino, N. (2015). Impact of the DRG-Based Reimbursement System on Patient Care and Professional Practice: Perspectives of Swiss Hospital Physicians. Swiss Med Wkly. Volume 145. Week 14080.

13. Mathauer, I. \& Wittenbecher, F. (2013). Hospital Payment Systems Based on Diagnosis-Related Groups: Experiences in Low-and Middle-Income Countries. Bulletin of the World Health Organization. Volume 91,746-756A.

14. Mutia, M. (2016). Hubungan Antara Sistem Pembayaran Langsung dan Ina-CBGs dengan Kualitas Pelayanan Kesehatan Pasien Rawat Jalan di RSUD Dr. Moewardi. Universitas Sebelas Maret.

15. Or, Z. (2014). Implementation of DRG Payment in France: Issues and Recent Developments. Health Policy. Volume 117, 146-150.
16. Peprah, A. A. \& Atarah, B. A. (2014). Assessing Patient's Satisfaction using SERVQUAL Model: A Case of Sunyani Regional Hospital, Ghana. International Journal of Business and Social Research. Volume 4, 133-143.

17. Rauner, M. S. \& Schaffhauser-Linzatti, M. M. (2013). Impact of Inpatient Reimbursement Systems on Hospital Performance: The Austrian Case-Based Payment Strategy. Operations Research and Health Care Policy. Springer.

18. RSUD Dr. Iskak Tulungagung. (2015). Profil RSUD Dr. Iskak Tulungagung Tahun 2015. Tulungagung: RSUD DR. Iskak Tulungagung

19. Wild, V., Pfister, E. \& Biller-Andorno, N. (2012). Ethical Research on the Implementation of DRGs in Switzerland-a Challenging Project. Swiss Med Wkly. Volume 142. Week 13610.

20. Yavari, M., Azimi, L., Khosro Abadi, G., Baladast, M., Salaj Mahmoudi, S. \& Vahidi, S. (2015). Hospital Income Loss due to Incomplete Clinical Documentation: A Survey of Service Items and Potential Causes in the Iranian Teaching Hospitals. International Journal of Hospital Research. Volume 4, 137-142. 